\title{
A ECONOMIA SOLIDÁRIA E A REVITALIZAÇÃO DO PARADIGMA COOPERATIVO
}

\section{Luiz Inácio Gaiger}

O termo economia solidária ganhou expressão no Brasil ao longo dos anos de 1990, à medida que iniciativas econômicas despontaram no país, notabilizando-se e sendo reconhecidas por sua natureza associativa e suas práticas de cooperação e autogestão. Expandindo-se, a economia solidária veio a abranger categorias sociais e modalidades diversas de organização, tais como unidades informais de geração de renda, associaçõos de produtores e consumidores, sistemas locais de troca, comunidades produtivas autóctones e cooperativas dedicadas à produção de bens, à prestação de serviços, à comercialização e ao crédito.

Segundo trabalhos de referência e pesquisas empíricas abrangentes, a primazia que esses empreendimentos concedem à solidariedade se manifesta, em primeiro lugar, no envolvimento cotidiano de seus membros, na socialização dos recursos produ-

Artigo recebido em 02/06/2011

Aprovado em 12/07/2012 tivos e na adoção de princípios de equidade (Guerra, 2002; Pinto, 2006; Gaiger, 2011). Quando estendida ao seu entorno, a solidariedade estimula sistemas mais amplos de reciprocidade, nos quais as vivências concretas de gestão do bem comum conferem um novo valor às noçôes de justiça e de interesse público (Gaiger e Laville, 2009). O agir coletivo da economia solidária institui, então, novos sujeitos no mundo do trabalho, nas estratégias de classe e nas lutas da cidadania, em resposta a anseios de bem-estar, reconhecimento e vida significativa (Veronese, 2008; Santos, 2010).

Esse artigo focaliza as cooperativas de economia solidária, modelo para o qual converge a maior parte dos programas de promoção de iniciativas nesse campo, embora nele se concentrem controvérsias agudas sobre a natureza e o valor social de tais experiências. Se for justo dizer que uma nebulosa de opiniōes e teorias paira sobre a economia solidária (Leite, 2009, p. 39), um dissenso maior reina so- 
bre as cooperativas, o que não surpreende quando se tem em vista que a história do cooperativismo foi motivada por aspiraçóes, projetos e concepçôes diferentes, nos quais radicam avaliaçôes contrastantes sobre seu sentido e suas virtudes. $\mathrm{O}$ surgimento de cooperativas populares no bojo da economia solidária, em uma época precisamente de flexibilização das relaçôes de trabalho e de predomínio do cooperativismo empresarial e de resultados, não as livraria de suspeitas e de interpretações díspares, apenas atenuáveis com o avançar dos fatos e das pesquisas.

É indiscutível que o cooperativismo nasceu no mesmo berço das lutas sindicais e político-partidárias, nas quais ganhou forma e vigor o movimento operário. Nenhuma dessas três frentes conduziu aos epílogos revolucionários, ardorosamente esperados e preconizados como via de passagem ao socialismo; nenhuma escapou a desvirtuamentos e instrumentalizações, por vezes com desenlaces trágicos. Mas nenhuma, tampouco, deixou de afetar radicalmente a face do capitalismo e de alimentar aspirações e ideais que seguem impelindo indivíduos e coletividades a lutarem contra a iniquidade e a desumanização.

Em suas realizações e vicissitudes, essas estratégias não comportam julgamentos únicos ou definitivos. Dado o estado das questões quanto às cooperativas solidárias no Brasil, estima-se que uma análise retrospectiva, tanto da economia solidária (seção 1), quanto do cooperativismo (seção 2), possa discernir fenômenos que se entrecruzam nessa realidade, elucidar situações e desfazer alguns nós que tornam improdutivo o debate (seção 3). A seguir, o artigo trata de caracterizar as cooperativas de trabalho situadas no campo da economia solidária e retomar algumas das questôes polêmicas a respeito (seção 4), com destaque ao problema das relações contraditórias entre as cooperativas e as estruturas econômicas, enfatizado em particular pela literatura marxista (seção 5).

Além de aquisiçōes da bibliografia sobre a economia solidária, hoje em franca expansão, o trabalho retoma sucessivas pesquisas empíricas do autor, às quais agrega análises mais recentes dos dados do primeiro Mapeamento Nacional da Economia Solidária, concluído em 2007. Até então, a inexistência de informaçôes abrangentes e sistematizadas sobre os empreendimentos solidários restringiu as pesquisas a uma abordagem qualitativa, valiosa para o exame de traços peculiares dessas organizações, mas insuficientes para aquilatar as características predominantes e efetivamente singularizantes dos empreendimentos. O Mapeamento permite uma mudança de escala nas análises e a rediscussão de questôes de outro modo tendentes ao impasse, como se pretende demonstrar. ${ }^{1}$

\section{Origens e sentidos da economia solidária}

Especialmente nos países periféricos em relação ao centro hegemônico mundial, sempre subsistiram práticas econômicas fundamentadas no trabalho e escoradas em laços de reciprocidade, nas quais a produção material atende a necessidades coletivas e guarda um sentido primordialmente social. Desde o século XIX, em paralelo ao domínio do capitalismo, estratégias associativas e cooperativas têm buscado assegurar condições de vida a importantes contingentes e, ademais, vêm mantendo vigentes princípios de produção de bens, de organização do trabalho e de circulação da riqueza distintos da racionalidade estrita do capital. A economia solidária reedita essa estratégia histórica dos trabalhadores, vinculada umbilicalmente ao movimento operário em seus primórdios, mas dele posteriormente cindida em muitos lugares, por óbices políticos mais do que por singularidades supostamente irredutíveis.

A perseverança e os desdobramentos desta estratégia, em prol de um "sistema republicano e beneficente de associação de produtores livres e iguais" (Marx, [1866] 1982), permitem aludir a um paradigma cooperativo, cuja longevidade explica-se por sua consistência e insistência utópica, assim como por seu pragmatismo e abertura diante das mudanças constantes nas sociedades em que prosperou (Namorado, 2007). ${ }^{2} \mathrm{O}$ cooperativismo de trabalhadores sofreu distorções, conheceu reveses e viveu períodos de estagnação. Ainda assim, sua história exprime simultaneamente a impossibilidade e a recusa, por parte dos trabalhadores, de viverem encerrados em uma lógica social fundada no utilitarismo e na renúncia ao cultivo de vínculos sociais desde o terreno da vida material. 
Somente uma teorização que considere a solidariedade como um princípio de ação coletiva independente, distinto do agir instrumental e estratégico, tem condiçóes de compreender a originalidade do que se expressa nas práticas associativas. A solidariedade remete à liberdade positiva de se desenvolverem práticas cooperativas e ultrapassa, pela busca das condiçôes intersubjetivas da integridade pessoal, a lógica do interesse (Chanial e Laville, 2009, p. 21-22).

Os estudiosos da economia solidária no Brasil convergem quanto às transformaçōes históricas que tiveram maior impacto sobre o aparecimento e a revitalização de práticas associativas e cooperativas. No inventário macroeconômico do último quartel do século XX, citam-se, em primeiro lugar, as mudanças no modelo de acumulação capitalista, por seus efeitos sobre a reconfiguração mundial dos mercados, as estruturas e cadeias produtivas e a geopolítica. A isto se vincula a crise de grande magnitude que então atingiu o sistema de trabalho assalariado, cujos reflexos têm sido ondas de desemprego em larga escala e de insegurança econômica, impelindo os trabalhadores à busca de alternativas de ocupação e renda.

No plano ideológico e político, o descrédito das experiências socialistas e da via revolucionária colocou em xeque a forma de intervenção das correntes e organizações políticas, o que, superado o momento inicial de perplexidade e desorientação, viria ajudar a desobstruir o caminho em direção a novas experiências sociais e a novos esquemas de análise e de formulação estratégica. No Brasil, tais problemas deixaram de ser apenas retóricos, à medida que forças políticas de esquerda chegaram ao poder e viram-se compelidas a dar respostas à sua base social, conforme apregoado em seus programas de governo. Paralelamente, a evolução das experiências solidárias pioneiras, atestando sua viabilidade e capacidade de trazer benefícios a seus integrantes e entornos sociais, despertou a sensibilidade de ativistas e intelectuais, instaurando um clima estimulante, no qual se multiplicaram agentes de promoção da economia solidária.

Essas condiçôes históricas gerais, embora tenham definido conjunturas propícias à gênese da economia solidária, seriam ineficazes sem a presença de outros fatores mais próximos aos protagonistas dos acontecimentos, constitutivos de seu campo de experiências, cujos efeitos combinados resultaram nesse novo campo de práticas. Tendo essas questōes em vista, uma pesquisa em diversas regiōes do Brasil (Gaiger, 2004) concluiu que o surgimento de empreendimentos econômicos solidários é mais provável diante de algumas circunstâncias específicas. Entre elas, o fato de envolver setores populares dotados de referências culturais e de lideranças genuínas que valorizam a vida comunitária, o associativismo ou as mobilizaçóes de classe, sobretudo quando tais referências se alimentam em vivências próprias de organização e luta, nas quais esses protagonistas forjaram identidades comuns, laços de confiança e competências para a defesa coletiva de interesses e aspirações. Assim, as cooperativas populares, oriundas de lutas sociais, ao contrário daquelas induzidas externamente, além de exibirem melhores indicadores econômicos, apresentavam maior solidariedade comunitária e maior inserção política na sociedade.

Outro fator decisivo, de ordem ao mesmo tempo material e cultural, diz respeito à compatibilidade entre os modelos autogestionários e as práticas econômicas populares usuais, com seus respectivos arranjos semicoletivos, familiares ou individuais, que asseguram a subsistência e fazem parte da experiência prévia e dos círculos de relacionamento e influência social dos trabalhadores. Salvo raras exceçōes, os empreendimentos solidários não substituem integralmente nem prescrevem as formas populares de economia, mas as potencializam, à medida que reorganizam os fatores produtivos, materiais e humanos, em um processo de metamorfose (Gaiger, 1996; Hespanha, 2010) normalmente incompleto e essencialmente híbrido. Por conseguinte, as práticas de economia solidária não se definem necessariamente em contraposição frontal à economia capitalista, mas deveras se opõem ao caráter historicamente subalterno que ela e as formas degradadas de economia popular, por razóes diversas, reservam a quem vive do seu trabalho.

A atuação de entidades e grupos de mediação, eficientes em canalizar as demandas dos trabalhadores para alternativas associativas e autogestionárias, constitui outro requisito. A competência decisiva 
dos agentes externos consiste em acionar instrumentos pedagógicos e materiais que impulsionem as experiências populares a transitar de uma lógica de preservação e defesa das condições já dadas de existência, orientadas pela recomposição das formas de vida conhecidas, para uma lógica de emancipação social e econômica, que implica rupturas progressivas com a condição de subalternidade. Tal processo comporta uma remodelação gradual das aspiraçôes, dos padrões materiais de subsistência e da lógica econômica de reprodução simples da economia popular (Gaiger, 1996), sendo um desafio, quase invariável, impedir que personalismos, tendências autoritárias e mediações externas resultem em situações de tutela dos trabalhadores (Holzmann, 2012).

A atuação das lideranças e dos agentes externos é favorecida pela formação de um cenário político e ideológico que reconheça a relevância dessas novas demandas e das alternativas que apontam, as quais passam a penetrar em amplas frações dos movimentos sociais e da institucionalidade política. Entretanto, o impacto positivo dessas novas forças não se verifica a contento sem que as experiências disponham de um lastro próprio e sem que um largo percurso já tenha sido percorrido, projetando a economia solidária para o debate na sociedade. Uma vez alcançado esse patamar, ações de envergadura tornam-se factíveis, principalmente no âmbito das políticas públicas.

Por fim, os participantes dos empreendimentos solidários em geral mostram ressentir-se pessoalmente da redução das modalidades convencionais de subsistência, seja devido à menor absorção ou maior seletividade do mercado de trabalho, seja devido à ineficácia das políticas destinadas a gerar oportunidades econômicas ou a compensar sua insuficiência. Essa ordem de fatores, embora seja muito enfatizada pela literatura para explicar a gênese da economia solidária, em verdade apenas causa esse efeito se combinada com as circunstâncias anteriores. Situações de desamparo tão somente agravam os problemas dos trabalhadores, sem conduzir espontaneamente a qualquer solução particular, cuja escolha, mesmo se inopinada, depende de predisposiçôes e aspirações específicas. Épocas de crise não têm engendrado saídas associativas orga- nizadas e duráveis com a magnitude que se observa atualmente, de sorte que menosprezar os outros fatores concorrentes e satisfazer-se com a clássica versão das "formas de resistência ao desemprego" significa finalizar a explicação onde ela devia apenas começar.

$\mathrm{Na}$ última década, a economia solidária suscitou muitas iniciativas com o fito de promovê-la como um instrumento de geração de renda e de coesão social. Ela se converteu em objeto tanto de políticas públicas específicas quanto de programas transversais. O campo da economia solidária constitui-se hoje de quatro segmentos principais: a) os empreendimentos solidários, com atividades econômicas de produção, prestação de serviços, comercialização, finanças e consumo. O Mapeamento Nacional registrou quase 22 mil empreendimentos, com 1,6 milhões de sócias/os e mais de 500 mil postos de trabalho; b) as organizaçôes civis de apoio à economia solidária, contando-se inúmeras ONGs, universidades, entidades sindicais e organismos de pastoral social, cuja atuação pioneira data dos anos de 1980; c) os órgãos de representação e articulação política dos diversos segmentos $\mathrm{e}$ atores, no âmbito dos movimentos sindicais, das incubadoras, dos gestores públicos, das entidades de crédito solidário, das redes de troca etc., com destaque ao Fórum Brasileiro (FBES), central nos debates e mobilizações nacionais; d) os organismos estatais à testa de programas públicos de economia solidária. Como órgão maior da esfera pública, sinalizando o nível de institucionalização alcançado, tem-se desde 2006 o Conselho Nacional de economia solidária, com representações de setores do Estado e da sociedade civil.

Estudos sobre a ação pública na economia solidária, seus fóruns e articulaçôes (França Filho et al., 2006; Santos, 2010; Edelwein, 2011), indicam sua eficácia em fortalecer redes e movimentos sociais, abrir canais de atendimento a demandas coletivas e forjar dispositivos institucionais voltados à participação direta. As razões mais profundas dessa vocação política radicam na vivência cotidiana dos integrantes dos empreendimentos, que os conduz a buscarem soluçôes por intermédio da sua auto-organização. Em contrapartida, fazer-se presente na cena política valoriza a imagem dos empreen- 
dimentos, ao mesmo tempo em que lhes confere legitimidade e meios de disputar recursos. O protagonismo na cena pública é assim motivado por razōes político-ideológicas e pragmáticas.

Debates constantes travam-se entre lideranças, militantes e acadêmicos acerca do papel e dos rumos da economia solidária. Não obstante perdurem controvérsias, o avanço das experiências provocou gradativos câmbios de enfoque. Há pouco mais de dez anos, eram vistas como respostas emergenciais, lenitivas diante da pobreza e do desalento, não constituindo senão uma resposta defensiva, de resistência. Nos dias atuais, admite-se que as experiências solidárias encerram uma dimensão propositiva, com reflexos efetivos no campo das políticas públicas e no fortalecimento político dos movimentos sociais implicados em construir alternativas pós-capitalistas. Com as posições mais céticas ou entusiastas enfraquecidas, cresceu a sensibilidade à natureza contraditória dos processos de transformação social e à compatibilidade entre os papéis exercidos pela economia solidária diante da ordem econômica e social vigente, tal como se verificara historicamente com as experiências cooperativas (Namorado, 2007, p. 10): ser instrumento de compensação e de equilíbrio, ser forma de resistência à lógica dominante e ser um espaço propulsor de alternatividade.

\section{A economia solidária e a evolução do cooperativismo}

Entre outras vertentes, a economia solidária manifesta-se em uma nova geração de cooperativas, designadas de populares ou de economia solidária. $\mathrm{O}$ Mapeamento Nacional registrou, em 2007, mais de 2.100 cooperativas, equivalentes a 9,7\% dos empreendimentos recenseados. Em sua maior parte, essas cooperativas haviam iniciado suas atividades nos quinze anos anteriores ao Mapeamento, motivadas em boa medida pela convicção de que esse formato constitui idealmente o modelo mais acabado de autogestão e de solidariedade econômica, sendo a base de um sistema adequado para atender aos interesses dos trabalhadores (Culti, 2008). ${ }^{3}$ Ao mesmo tempo, elas se têm alinhado em favor de um novo modelo, ao questionarem o perfil político e os principais impasses do cooperativismo no país, relacionados com a coerência entre seus princípios doutrinários e seu desenvolvimento histórico.

Desse ponto de vista, a exemplo das ações conduzidas pelo Movimento dos Trabalhadores Sem Terra, o objetivo tem sido propugnar um novo cooperativismo. Como obra de trabalhadores cooperados, ele viria suplantar o cooperativismo tradicional e recuperar as cooperativas desvirtuadas pela centralização do poder ou criadas de modo fraudulento, como um estratagema empresarial de desoneração de custos sociais. O êxito dessas estratégias e a viabilidade das cooperativas solidárias dependem das virtualidades decorrentes da natureza específica desse tipo de organização e do seu potencial para gerar ambientes socioeconômicos que não a ameacem, mas a fortaleçam, convertendo-a em um nódulo diferenciado e expansível no interior do sistema econômico atual. Discutir essa perspectiva, em pauta nos debates sobre o contributo das cooperativas, implica antes sumariar a trajetória do cooperativismo no Brasil, no sentido de discernir situações e problemas diferentes.

O cooperativismo foi originalmente introduzido no Brasil por imigrantes europeus, no final do século XIX, principalmente nas regiōes Sul e Sudeste, como estratégia para superar as situaçōes de flagrante desamparo em que viviam. Nestes primórdios, surgiram as cooperativas de consumo, as primeiras registradas oficialmente, bem como as de crédito e as agropecuárias, especialmente nos estados do Rio Grande do Sul, São Paulo e Rio de Janeiro. As cooperativas de consumo expandiram-se nas décadas de 1950 e 1960. Na época, apenas $45 \%$ da população concentrava-se nas regióes urbanas, nas quais se projetaram as cooperativas de crédito e serviços, apresentando-se inicialmente mais dinâmicas que as do setor agropecuário.

Posteriormente, o panorama se modificaria. Nos anos de 1960, o cooperativismo urbano apresentou sinais de estagnação, atribuível ao desestímulo oficial, tanto no plano legal quanto naqueles de crédito e assistência técnica, o que resultou em uma série de barreiras à sua expansão e sobrevivência. O modelo de desenvolvimento predominante ao longo do século XX é outro fator explicativo do 
declínio dessas cooperativas, ao ter gradativamente propiciado a expansão das grandes empresas capitalistas, estimulando a proliferação de complexas redes de supermercados, organismos financeiros, seguradoras etc., que substituíram os serviços antes prestados pelas cooperativas (Schneider e Lauschner, 1979).

Por sua vez, as cooperativas agropecuárias surgiram e se desenvolveram em um contexto econômico rural formado por núcleos de imigrantes. Elas foram paulatinamente estimuladas pelo governo com vistas à ampliação da produtividade agrícola, em resposta ao crescimento demográfico e em virtude do imperativo de incrementar as exportaçôes. ${ }^{4}$ Neste cenário, de incentivo às cooperativas agropecuárias, os demais ramos do cooperativismo sofreram redução drástica. Desde 1970, o declínio das cooperativas também se deveu à intensificação do ritmo de agregação (sobretudo fusōes e incorporações) estimulada pela legislação cooperativista. Ademais, as exigências competitivas impostas pelo mercado, internacional e interno, tornaram cada vez menos viável a sobrevivência de cooperativas com pequena capacidade de produção e comercialização. O tipo de cooperativismo agrícola que desde então predomina no Brasil tem reproduzido o domínio de uma elite conservadora, voltada a uma economia basicamente agroexportadora - hoje, o agrobusiness. Esse quadro esteve amparado em uma política de controle social e de intervenção estatal que não trouxe mudanças significativas para os trabalhadores cooperativados no meio rural. Ao contrário, o modelo contribuiu para a concentração da propriedade fundiária e para instilar a desconfiança entre os pequenos agricultores acerca do cooperativismo (Schneider e Lauschner, 1979).

Para esses agricultores, as cooperativas serviram décadas atrás como instrumentos coletivos de desenvolvimento econômico e de fortalecimento comunitário, mantendo-se acessíveis e próximas aos seus interesses. Já o cooperativismo agropecuário moderno converteu-se em um mecanismo de aliança empresarial, extremamente sensível ao poder econômico. Tais cooperativas resumiram-se a uma modalidade de empresa econômica, visando a reforçar o poder de classe dos produtores rurais e a garantir melhor barganha dos recursos públicos, do que decorreu sua forte dependência das políticas de governo e da habilidade de suas lideranças em transacionar com as forças políticas do Estado. ${ }^{5}$

Ao final dos anos de 1970, o cooperativismo adquiriu novo alento com a criação de muitas cooperativas de trabalho. Este movimento generalizou-se na década de 1980, em reação ao desemprego estrutural e à insolvência de empresas, provocados pelas mudanças tecnológicas e organizacionais, mas também abrangeu formas alternativas de produção, a exemplo das fábricas recuperadas ou de autogestão operária (Lima, 2006). Os primeiros antecedentes do cooperativismo de trabalho datam, no entanto, de 1932. A partir 1965 , começaram a aparecer cooperativas de profissionais qualificados, como médicos, dentistas e professores, almejando solucionar problemas de inserção no mercado de trabalho (Culti, 2008). No instante da maior proliferação das cooperativas de trabalho, verificada nas décadas de 1980 e 1990, vários estudos indicaram serem elas majoritariamente um meio de tornar flexíveis as relaçôes de trabalho, terceirizando serviços e buscando reduzir custos de mão de obra (Lima, 2002, 2008; Piccinini, 2004; Pontes, 2007).

As peculiaridades das cooperativas de trabalho efetivamente mantidas sob o comando dos produtores diretos foram reconhecidas apenas ao final dos anos de 1990. O fato conduziu uma parcela dos autores a relativizar as teses no geral pessimistas sobre o caráter e as possibilidades de desenvolvimento dessas cooperativas, passando a vê-las como alternativa de ocupação e renda, "um caminho em que a autogestão constitui uma possibilidade frente ao assalariamento, sem que ela necessariamente signifique precarização" (Lima, 2009, pp. 94-95). Do ângulo da condução política do cooperativismo, o reflexo foi sua progressiva aproximação à nova linguagem da economia solidária e às suas organizações, em particular em certas secções do cooperativismo de trabalho.

Hoje, o cooperativismo brasileiro apresenta-se heterogêneo quanto à natureza e à escala de suas atividades, à complexidade das organizaçóes cooperativas e, fundamentalmente, a seus princípios de gestão e suas orientações ideológicas. Grandes cooperativas funcionam como empresas de capital, voltadas à lucratividade no mercado, empenhadas 
na profissionalização e na racionalização administrativa e valendo-se de modernas tecnologias para lograrem ganhos em escala e eficiência. No extremo oposto, pequenas cooperativas nas periferias urbanas, voltadas à inserção socioeconômica e a necessidades básicas de populaçôes pobres, manifestam uma índole igualitarista e valorizam o fato de governarem-se participativamente (Nunes, 2001; Anjos, 2009). Por seu turno, as vertentes mais antigas do associativismo rural expressam-se através de um sem-número de associações de apoio à produção familiar. Tais iniciativas permanecem, via de regra, restritas em seus fins e espaços de atuação, mas têm preservado a cultura associativa no meio rural, lastreando as iniciativas que hoje prevalecem entre os empreendimentos registrados pelo Mapeamento da Economia Solidária.

As controvérsias no meio político e acadêmico especializado decorrem em parte do fato de que o cooperativismo, a esse ponto heterogêneo, não comporta diagnósticos e prognósticos únicos. Três situações ao menos deveriam ser visualizadas: as cooperativas empresariais, nas quais os cooperados são proprietários, mas não trabalhadores da cooperativa, ou cooperam em prol de suas empresas privadas; as cooperativas de fachada, que se valem do marco legal cooperativo para intermediarem mão de obra a baixo custo, mantendo a divisão social entre capital e trabalho e operando com práticas de subassalariamento; e as cooperativas genuinas, nascidas de um ato associativo premeditado e deliberado por trabalhadores ou consumidores, com o fim de proverem renda, bens ou serviços, funcionando por meio de instâncias coletivas e paritárias de decisão.

As cooperativas empresariais atuam seguindo prioridades e estratégias similares às empresas convencionais de mercado, confundindo-se com elas no cenário concorrencial em que operam os agentes econômicos. Nem por isso ficam necessariamente destituídas de processos de gestão democráticos e participativos, bem como do princípio de equidade no exercício do poder decisório e na divisão dos benefícios trazidos pela operação econômica. Provavelmente, como se pode observar em cooperativas agropecuárias ou naquelas de prestação de serviços de saúde, os interesses individuais e pragmáticos dos sócios terminam sobrepondo-se à identidade e aos objetivos comuns. Em resultado, a base social da cooperativa se fragiliza e finda, delegando o poder gestor, e também condutor, a um grupo restrito. A despeito das intençôes, esses fatos sinalizam os impasses com que se deparam as cooperativas em seu processo de crescimento no interior de economias de mercado capitalistas ou, ainda, aqueles decorrentes de estarmos em sociedades de livre-arbítrio, implicando a necessidade de conciliar constantemente interesses e visōes particulares no interior do quadro social cooperativo.

As cooperativas de intermediação de mão de obra instituídas à revelia dos trabalhadores, com vistas à flexibilização e ao barateamento da força de trabalho, revestem-se apenas de um interesse negativo para nossa discussão. Esse e outros subterfúgios foram utilizados no quadro do regime de acumulação flexível do capitalismo, sobretudo em países com institucionalidade e controle social deficientes. Por conseguinte, o que está em jogo é a descaracterização dos princípios cooperativos, não a pretensa, mas falaciosa, existência de organizaçôes cooperativas. Antes de advogar a funcionalidade em geral das cooperativas para o capital, cabe discernir o que nelas se mostra um efeito direto, positivo ou negativo, das práticas autogestionárias, da sua insuficiência ou, pelo contrário, da sua cabal inexistência, camuflada sob o rótulo cooperativo afixado pelas empresas. Guardar essas diferenças, como frisa Leite (2009, p. 14), evita sustentar polêmicas com base em julgamentos unilaterais ou categóricos, opondo falsas e verdadeiras cooperativas. O cooperativismo de trabalho não se encontra isento de ambiguidades, mas é preciso sopesar os artifícios patronais de aviltamento do trabalho, determinantes em alguns casos, e as numerosas e árduas tentativas de construção de alternativas de renda que propiciem ao mesmo tempo uma vivência de autonomia e de participação.

No campo das dificuldades de instaurar um projeto cooperativo, e a despeito do idealismo por vezes reinante, as cooperativas de trabalho mostram-se estruturalmente vulneráveis quando suas atividades laborais são individualizadas, pois assim conduzem a envolvimentos recíprocos limitados e a vínculos de caráter contratual. Em tais circunstâncias, a gestão converte-se na arte de fazer arranjos 
constantes entre interesses particulares e momentâneos, sobretudo na situação corriqueira em que a cooperativa apenas oferece uma ocupação complementar ou temporária aos associados. ${ }^{6}$ Em compensação, essas cooperativas atenuam os riscos de insolvência com relativa desenvoltura, pois se lhes resulta mais fácil conciliar os interesses e ganhos individuais, ambos variáveis, com os imperativos de preservação do capital da empresa. O custo, no entanto, é a fragilidade do vínculo associativo e o arrefecimento das condutas direcionadas às necessidades e aspiraçôes coletivas (Gaiger, 2006). O peso de fatores que fogem ao controle e às soluções internas das cooperativas também as deixa suscetíveis a descaminhos. $\mathrm{O}$ fato, porém, não pode ser atribuído sem mais à sua natureza social e autogestionária, nem significa que estejam desprovidas de qualidades apreciáveis ante as condições de trabalho e vida dos trabalhadores, no contexto das alternativas de que realmente dispóem. ${ }^{7}$

Esse estado de coisas mantém inconcluso o debate em torno das potencialidades emancipatórias das cooperativas. Não cauciona as teses mais otimistas quanto ao seu caráter revolucionário, na linhagem de pensamento inaugurada pelos socialistas utópicos e continuada por um leque amplo de correntes centradas nas ideias de autonomia operária e autogestão. Como Marx previra, as cooperativas não se apresentaram por si sós em condições de transformar a sociedade capitalista, e várias delas equiparam-se a "simples sociedades anônimas burguesas". Mas isso não o impediu de recomendar aos operários "que se metam na produção cooperativa", posto que, em relação ao sistema econômico presente, ela "ataca seu alicerce" (Marx, [1866] 1982). ${ }^{8}$

A julgar por certos países, sobretudo a emblemática história do Canadá, do Québec ao Oeste (Fairbairn, 2004), as cooperativas tampouco enveredaram inexoravelmente para sua dissolução, vitimadas pela inviabilidade histórica de empregarem o capital de forma não capitalista, conforme vaticinara Rosa de Luxemburgo. Se não foi assim, qual o contributo das cooperativas de trabalhadores nas atuais contingências históricas, não apenas em um imaginável futuro pós-capitalista? Talvez seja esse o efeito demonstrativo das experiências estimuladas ou nascidas sob a égide da economia solidária.

\section{A racionalidade das cooperativas solidárias}

Tais experiências cooperativas surgiram discretamente, sem adjetivarem-se de solidárias ou constituírem um movimento organizado. ${ }^{9}$ No correr dos anos de 1990, seu aparecimento a cada dia, em atividades de produção, prestação de serviços, crédito e comercialização, tornou inevitável sua contraposição ao perfil empresarial e ao conservadorismo político do cooperativismo tradicional. Além disso, chamou atenção para as artimanhas patronais de criação de falsas cooperativas, embates constantes se havendo registrado desde então no âmbito da justiça do trabalho. ${ }^{10}$ Discussóes também se desenrolaram no movimento sindical, recordando-se a história e os valores seminais das lutas operárias, do que decorreram iniciativas de apoio, em particular no sindicalismo cutista.

Ao término da década, uma nova geração de cooperativas havia surgido nos interstícios do cooperativismo tradicional, ou em franca contestação a ele, de algum modo sendo reconhecida ou impelida pelo amplo conjunto de iniciativas que já gravitavam em torno da economia solidária. $\mathrm{O}$ Mapeamento Nacional coletou informaçôes sobre 2.111 cooperativas, das quais $40 \%$ tinham até 30 sócios, e $64 \%$, até 65 sócios, cifras que no último ano haviam decrescido em apenas $18 \%$ das cooperativas, ampliando-se em $41 \%$ delas. Suas atividades relacionavam-se com agricultura e pecuária, fabricação de alimentos, produtos têxteis ou de madeira, comércio, reciclagem, prestação de serviços e intermediação financeira. A atuação coletiva das cooperativas mapeadas abrangia os campos mostrados na Tabela $1 .^{11}$

As cooperativas solidárias destinam-se muitas vezes a sustentar atividades produtivas individuais ou familiares dos cooperados. No ano anterior à coleta de dados, $43 \%$ das cooperativas apresentaram saldo financeiro, contra $16 \%$ com resultados negativos. Mais de $78 \%$ declararam ter recebido algum tipo de apoio técnico ou político externo, de órgãos de governo, entidades civis, incubadoras, universidades ou organizações sindicais. Seu razoável desempenho, como vimos, ensejou maior receptividade às teses que valorizam a economia solidária como um novo esteio para o fortalecimento das lu- 
Tabela 1

Campos de Atuação Coletiva das Cooperativas

\begin{tabular}{lll}
\hline Campos de atuação & $\begin{array}{l}\text { Número de } \\
\text { cooperativas }\end{array}$ & $\begin{array}{l}\text { Percentual de } \\
\text { cooperativas }\end{array}$ \\
\hline Produção & 1076 & $51 \%$ \\
\hline Prestação de serviços (ou trabalho) & 873 & $41,1 \%$ \\
\hline Comercialização & 1176 & $55,7 \%$ \\
\hline Troca de produtos ou serviços & 175 & $8,3 \%$ \\
\hline Uso de equipamentos & 986 & $46,7 \%$ \\
\hline Uso de infraestrutura & 1.090 & $51,6 \%$ \\
\hline Aquisição de matérias-primas ou insumos & 728 & $34,5 \%$ \\
\hline Poupança ou crédito & 326 & $15,4 \%$ \\
\hline Obtenção de clientes ou serviços & 487 & $23,1 \%$ \\
\hline
\end{tabular}

Fonte: Sistema de Informações sobre Economia Solidária - Senaes/MTE, 2007.

tas populares. Para que essa expectativa não se limitasse a conjecturas, era necessário colocá-la à prova dos fatos já manifestos na realidade dos empreendimentos. Tratava-se de investigar se o novo associativismo popular, impelido em boa medida por imposição das circunstâncias, poderia converter-se no elemento básico de uma racionalidade econômica específica, capaz de sustentar os empreendimentos por meio de resultados efetivos, portanto sem reduzi-los a um ato voluntarista, com poucas chances de persistir e angariar adesão social. Caso fosse possível aquilatar forças vitais aos empreendimentos solidários, derivadas de suas singularidades organizacionais e vantajosas perante outras formas de agenciamento do trabalho e de produção econômica, com mais propriedade se poderia estimar as suas possibilidades de desenvolvimento.

Nossas pesquisas vêm sucessivamente abordando a questão e levam a uma linha de entendimento expressa na seguinte formulação geral: o êxito dessas iniciativas depende de sua capacidade de articular uma lógica empreendedora - de busca de resultados por meio de ação planejada e da otimização dos fatores produtivos, humanos e materiais e uma lógica solidária. Desta sorte, a cooperação funciona como vetor da racionalização econômica, produzindo efeitos tangíveis e vantagens reais diante da ação individual e da cooperação não solidária. ${ }^{12}$ A racionalidade produtiva em questão valer-se-ia então das potencialidades específicas do trabalho consorciado e da gestão coletiva. Quando ativadas, essas alavancas permitem que tais iniciativas se tornem superiores ao trabalho artesanal e individualizado dos pequenos produtores, mais produtivas do que as empresas convencionais e, sobretudo, mais recompensadoras do que a condição assalariada.

Estudos sobre diversos tipos de empreendimentos solidários sustentam essa convicção. Uma das pesquisas (Gaiger, 2001) traçou uma análise comparativa entre cooperativas de prestação de serviços, cooperativas de produção industrial e cooperativas de produção agrícola. A despeito da variada gama de atividades por elas desenvolvidas, um dos seus traços comuns residia no caráter do vínculo associativo, ligado indissoluvelmente à socialização do processo produtivo, no âmbito do trabalho e da gestão. $\mathrm{O}$ trabalho associado mostrou-se como cerne dos empreendimentos: por ser o trabalho a garantia básica das cooperativas, torna imperativo que a proteção àqueles que detêm capacidade laboral, e por isso associam-se, seja irrenunciável. $\mathrm{O}$ trabalho assume também um valor simbólico, ao proporcionar uma experiência 
referendada em ideais de justiça e equidade. Enriquecido do ponto de vista humano e cognitivo, traz satisfaçōes relevantes: a condição ímpar de ser coproprietário e gestor do negócio, de dispor de poder de decisão em prol do coletivo e de si, de recuperar a estima própria, de viver o trabalho, enfim, como algo edificante e dignificante.

Ainda assim, o contexto altamente seletivo da economia obrigava a indagar se as cooperativas dispunham de trunfos suficientes para sua sobrevivência e consolidação. Como o trabalho cooperativo estabelece um vetor econômico com efeitos diferenciais perante as formas convencionais de organização produtiva? Resumindo as conclusōes a respeito em duas proposições: a) o êxito econômico dos empreendimentos mostra-se vinculado a condições cujo efeito positivo deriva proporcionalmente do seu caráter socialmente cooperativo, significando que a solidariedade no trabalho funciona como um vetor específico da competitividade e viabilidade das cooperativas; b) apesar da modesta margem de produção de excedentes, as cooperativas solidárias apresentam indicadores não desprezíveis de eficiência econômica e se inclinam a distribuir seus resultados equitativamente (Gaiger, 2001).

Estudos posteriores (Gaiger, 2004, 2007a) evidenciaram que a função exercida pelos empreendimentos, em relação ao atendimento de necessidades dos seus integrantes e também em relação a aspiraçōes que possuam, constitui o elemento determinante da forma de organização adotada, da densidade dos seus vínculos solidários e da intensidade com que tais vínculos produzem os efeitos acima aludidos. $\mathrm{Na}$ extremidade superior do gradiente de satisfação, situam-se cooperativas autogestionárias baseadas na socialização integral dos meios de produção e em processos coletivos de trabalho. Sejam cooperativas industriais ou de produção agrícola, comportam os níveis mais elevados de autogestão e cooperação e assumem quase sempre um caráter essencial, dificilmente reversível, para a vida dos seus integrantes (Gaiger, 2004, p. 385).

Essa linha de argumentos coincide com um estudo à mesma época (Nunes, 2001), sobre o setor informal em aglomeraçóes urbanas e o papel de cooperativas situadas no mesmo contexto, com áreas de atuação e rendimentos semelhantes. Apesar dos ganhos modestos e do quadro precário de sobrevivência, nas cooperativas as fragilidades econômicas mostram-se contornáveis graças à qualidade do vínculo social construído a partir do trabalho. A "ideia de um 'nós' se constitui e a sua ação se faz presente na comunidade de referência do grupo", tornando as cooperativas "sensíveis a outras necessidades que não diretamente as suas." (Idem, p. 144-145). No referente à dignidade e à autoestima, as cooperativas favorecem o exercício da criatividade, com isso reduzindo o sofrimento e o sentimento de impotência, e deixando, pelo engajamento, afirmar-se uma nova identidade social (Idem, p. 154).

Tais constataçôes referendam estudos sobre os efeitos positivos da participação dos trabalhadores em cooperativas (Estrin, Jones e Svejnar, 1987; Defourny, 1988), em fábricas recuperadas (Santos, 2008) e em empresas socializadas pelo Estado (Espinoza e Zimbalist, 1984). ${ }^{13}$ Também convergem com um importante resultado de pesquisas mais recentes, realizadas sobre os dados do primeiro Mapeamento Nacional da Economia Solidária. Seus objetivos principais consistiram em identificar as características solidárias e empreendedoras dos empreendimentos e verificar até que ponto interagiam positivamente. Em termos conceituais, tratava-se de aferir a presença de uma racionalidade peculiar aos empreendimentos, derivada de sua natureza associativa e de elementos tais como a indivisão entre capital e trabalho, a autogestão e o entrelaçamento com movimentos sociais alinhados à construção da identidade política da economia solidária. Mantinha-se o mesmo objeto teórico dos estudos precedentes, porém com um novo enfoque metodológico.

A análise compreendeu os 21.855 empreendimentos mapeados. Seus componentes solidários e empreendedores foram examinados a partir das informaçōes coletadas pelo Mapeamento, tendo-se em vista as seguintes definiçôes, quanto à realidade interna e externa dos empreendimentos: por solidarismo, entenderam-se aspectos de autogestão (democracia, participação dos sócios e autonomia do empreendimento) e de cooperação (mutualidade, socialização dos meios de produção, gratuidade e envolvimento social); o empreendedorismo dizia respeito à eficiência (capacidade de operar econo- 
micamente, garantindo a sobrevivência da empresa no presente sem a comprometer no futuro) e à sustentabilidade (capacidade de gerar condiçōes para seguir funcionando a médio e longo prazo, sem transferir custos da operação à sociedade, como o uso de tecnologias poluentes).

Não obstante os empreendimentos tenham evidenciado índices modestos de atendimento a todos esses requisitos, apresentam uma congruência geral: a cada grau de empreendedorismo alcançado, corresponde um grau maior de solidarismo, os casos de desenvolvimento unilateral sendo minoritários. $\mathrm{O}$ estudo permitiu discernir as vias de convergência que progressivamente se estabelecem entre as práticas em questão: a partir da conquista de um patamar de gestão democrática, os empreendimentos lançam-se no papel de atores sociais da economia solidária, mediante engajamento comunitário e articulaçôes políticas e econômicas ou, numa segunda via, investem prioritariamente em políticas de valorização do trabalho, mediante remuneração regular, benefícios sociais e formação dos recursos humanos.

Esses caminhos não derivam apenas de determinaçōes objetivas, mas comportam escolhas políticas dos empreendimentos, influenciadas por sua identidade e seu projeto. As cooperativas demonstram maior afinidade com a segunda alternativa, o que se adéqua às suas feiçōes mais pragmáticas e suas preocupaçóes mais nítidas com metas de eficiência e de sustentabilidade. Entretanto, não se deveria esquecer que, conforme os dados, consolidar os mecanismos básicos de gestão democrática foi $\mathrm{o}$ primeiro passo requerido dos empreendimentos solidários bem-sucedidos, inclusive das cooperativas.

Somados os coeficientes, as cooperativas pontuarem acima dos demais empreendimentos, o que sinaliza uma conjunção mais forte entre os aspectos de autogestão, cooperação, eficiência e sustentabilidade (Tabela 2). ${ }^{14}$

As cifras das cooperativas apenas foram superadas quando se tomaram em separado os empreendimentos formados a partir da recuperação de empresas capitalistas (coeficiente integrado de 4,5143), cuja maioria adotou, precisamente, a forma cooperativa. Índices globais expressivos também foram alcançados por subconjuntos de empreendimentos relacionados com as cooperativas, como aqueles dedicados à poupança e crédito $(3,3418)$ ou à prestação de serviços $(3,3710)$. Da mesma forma, no caso de empreendimentos apoiados por organizaçóes que se dedicam preferencialmente à formação de cooperativas, a exemplo daqueles assessorados por entidades sindicais $(3,3581)$ ou, sintomaticamente, por cooperativas de técnicos $(3,5078)$, isto é, por outros empreendimentos solidários que adotaram o regime cooperativo como forma própria de organização.

A análise dos dados do Mapeamento, somada a estudos qualitativos mais localizados, converge com o balanço positivo das cooperativas: elas importam por seus resultados e porque se ligam por "uma sinergia natural às dinâmicas de natureza solidária" (Namorado, 2007, p. 29).

Tabela 2

Desempenho dos Empreendimentos Econômicos Solidários (EES) de acordo com a Forma de Organizaçáo

\begin{tabular}{llll}
\hline Forma de organização dos EES & $\begin{array}{l}\text { Coeficiente de } \\
\text { Empreendedorismo }\end{array}$ & $\begin{array}{l}\text { Coeficiente de } \\
\text { Solidarismo }\end{array}$ & $\begin{array}{l}\text { Coeficiente } \\
\text { Integrado }\end{array}$ \\
\hline Grupo informal & 0,7035 & 1,6526 & 2,3630 \\
\hline Associação & 0,6542 & 2,1471 & 2,8064 \\
\hline Sociedade mercantil & 1,006 & 1,9663 & 2,9862 \\
\hline Cooperativa & 1,3653 & 2,3434 & 3,7080 \\
\hline Total dos EES & 0,7525 & 2,0026 & 2,7600 \\
\hline
\end{tabular}

Fonte: elaboração do autor. 


\section{As cooperativas e as estruturas econômicas dominantes}

Entre as cooperativas registradas no Mapeamento, as de trabalho (compreendendo a produção e a prestação de serviços) predominam, perfazendo $1.331,70 \%$ delas tendo até trinta sócios ocupados laboralmente, e $87 \%$, até 65 membros ocupados. Sua saúde financeira supera a média dos empreendimentos no referente ao resultado econômico global, aos níveis de remuneração dos sócios e aos benefícios sociais. ${ }^{15}$ Embora o seu envolvimento sociopolítico externo fique ligeiramente aquém dos índices gerais, as cooperativas de trabalho possuem dispositivos mais sólidos de autogestão, inclusive em questôes de teor econômico estratégico. Esses elementos explicam o seu melhor desempenho solidário e empreendedor, antes referido, mas suscitam maior reflexão sobre o seu lugar nas atuais estruturas econômicas e sobre o papel vindouro do paradigma cooperativo.

Nos empreendimentos solidários - por força da lei nas cooperativas de trabalho - os sócios são juridicamente titulares da organização econômica, com direitos iguais a voz e voto. A esse respeito, os dados do Mapeamento apontam que apenas $15 \%$ dos empreendimentos possuem trabalhadores externos ao quadro social: a relação entre o total desses trabalhadores e o total de sócios é de 1/58 (1/17, quando se consideram unicamente os sócios ocupados regularmente nos empreendimentos). No caso das cooperativas de trabalho, é útil uma comparação com outros segmentos do cooperativismo no Brasil. Conforme a Tabela 3, o percentual de trabalhadores não sócios (empregados: assalariados permanentes ou temporários) em relação ao número de sócios equivale, no segmento tradicional das cooperativas agropecuárias, a quase $10 \%$. Ele decai abruptamente para uma relação de $1 / 45$ nas cooperativas de prestação de serviços (na Tabela 3, de Trabalho) e de 1/125 naquelas de produção.

Essa ampla predominância dos sócios no conjunto do pessoal ocupado significa que duas condições fundamentais da empresa e da lógica de produção capitalista se veem suspensas: a natureza privada (e apartada do trabalho) dos meios de produção e a existência de uma força de trabalho livre, despojada de meios de produção próprios e destituí-

Tabela 3

Número de Cooperativa, Cooperados e Empregados por Segmento - Brasil, 1998

\begin{tabular}{llll}
\hline Segmentos & $\begin{array}{l}\text { Número de } \\
\text { cooperativas }\end{array}$ & $\begin{array}{l}\text { Número de } \\
\text { cooperados }\end{array}$ & $\begin{array}{l}\text { Número de } \\
\text { empregados }\end{array}$ \\
\hline Agropecuário & 1.408 & 1.082 .378 & 107.086 \\
\hline Consumo & 193 & 1.412 .664 & 8.017 \\
\hline Crédito & 890 & 825.911 & 5.800 \\
\hline Educacional & 193 & 65.818 & 2.330 \\
\hline Energia e Telecomunicações & 187 & 523.179 & 5.161 \\
\hline Especial - escolar & 4 & 1.964 & 6 \\
\hline Habitacional & 202 & 46.216 & 1.226 \\
\hline Mineração & 15 & 4.027 & 24 \\
\hline Produção & 91 & 4.372 & 35 \\
\hline Saúde & 585 & 288.929 & 15.443 \\
\hline Trabalho & 1.334 & 227.467 & 5.057 \\
\hline Total & 5.102 & 4.428 .925 & 150.186 \\
\hline
\end{tabular}

Fonte: Organização das Cooperativas do Brasil - Detec/Banco de Dados. 
da de capital. Ficam entấo afastados dois requisitos essenciais ao funcionamento das relaçōes sociais de produção assalariadas. Quaisquer outras relaçôes de produção que as substituam não estão compelidas e nem são necessariamente aptas a cumprirem as mesmas funções: de extração e apropriação do trabalho excedente; de busca da máxima rentabilidade, com vistas à acumulação constante do capital; de mercantilização e instrumentalização do trabalho.

Conceitualmente, o rompimento das relações sociais de produção assalariadas abre para as cooperativas a possibilidade objetiva de constituírem, em seu âmbito interno, uma nova forma social de produção. Ou seja, uma nova estrutura de relaçôes mútuas entre os indivíduos implicados no processo de apropriação e transformação da natureza, relações determinadas pelo lugar social que eles ocupam em face das condiçôes e dos resultados dos diversos processos de trabalho (Godelier, 1981). Todo o modo de produção possui uma forma social de produção específica, além de outras que subsume e alinha à sua lógica, à medida que se torna dominante. Dessa maneira, a possibilidade de constituir ou manter outras formas é algo decisivo quando se têm em vista perspectivas consistentes de superação ou de criação de alternativas à estrutura econômica dominante. No âmbito da teoria da transição marxista, não é possível raciocinar abstraindo-se essas condiçōes. ${ }^{16}$

A começar pelo fato de não haver outro ambiente econômico senão o capitalista, condicionamentos extremamente fortes apresentam-se à contracorrente da forma social de produção cooperativa. As cooperativas deparam-se com poderosos óbices internos, legados pelo tipo singular de desenvolvimento histórico das forças produtivas e das relaçōes sociais de produção capitalistas, que se refletem no modo material de produção, na divisão do trabalho e na cultura fabril dos trabalhadores cooperados. Mas há diferenças importantes: nas relaçōes de produção cooperativas é improvável que o trabalhador não se sinta de algum modo reconciliado com os frutos do trabalho e em parte não supere, subjetivamente, um estado de alienação, cujas causas objetivas diretas se encontram embargadas. Já não faria sentido conceber o trabalho de modo instrumental ou eleger a lucro como objetivo máximo, à revelia de consideraçōes eticamente refletidas sobre o sentido da atividade econômica e sobre o limite a partir do qual se sacrificar por ela se torna ilógico. Assim, a economia tende a ser reinserida nas relações sociais, enfraquecendo sua componente racional utilitarista. Do mesmo modo, ela se reintegra à dimensão política da vida coletiva, estimulada pela autogestão cooperativa, à medida que promove a participação e socializa o poder no cotidiano dos empreendimentos.

A cooperação defronta-se ainda com um obstáculo histórico persistente: a divisão social do trabalho, que separa as funções de gestão e direção daquelas de execução e, no plano mais geral, exclui os encarregados diretos da produção das deliberações políticas e estratégicas de planejamento. Tais distinções, fundamentais à reprodução das classes sociais, sustentam hierarquias e desigualdades, incorporadas, aliás, também na vida política e nos partidos operários, nos quais dirigentes de origem intelectual ou ex-operários intelectualizados em geral "monopolizam toda atividade de direção, deixando aos militantes de base o trabalho político braçal" (Singer, 1981, p. 51).

Malgrado tais problemas, é notória a tendência dos empreendimentos solidários ao igualitarismo. Embora não suprimam as diferenças de remuneração, as atenuam e, sobretudo, eliminam as discriminações impostas contra trabalhadores menos produtivos e rentáveis para o capital, via de regra em consequência da própria usura do trabalho (Gaiger e Asseburg, 2007). Mesmo em contextos de severa dependência das cooperativas a externalidades que fogem ao seu controle, estudos têm detectado sua inclinação igualitária, seu intuito de evitar o "autoritarismo de fábrica" e seus logros em propiciar condiçôes de trabalho mais satisfatórias e democráticas (Lima, 2008).

Entende-se por que as cooperativas de produção, nas quais o desafio de instaurar novas relações sociais atinge o seu mais algo grau, sejam vistas por alguns autores como a modalidade elementar da economia solidária (Singer, 2002, pp. 83-84). Para vencer o desafio, requer-se do trabalho associado que funcione como uma força produtiva peculiar e incremental. As chances de alcançar esse novo padrão qualitativo crescem quando, além de incorpo- 
rar a base técnica capitalista, a forma cooperativa renova o conteúdo material do processo de trabalho, desenvolve novas forças produtivas, materiais $\mathrm{e}$ intelectuais, adaptadas às suas especificidades, e serve-se de métodos de administração e de critérios de redistribuição coerentes com sua natureza associativa e autogestionária.

Provavelmente nada teria a fazer uma empresa capitalista no epicentro do escravismo colonial. Uma forma social de produção apenas se desenvolve e se expande se transformações históricas mais amplas conduzirem a uma reorientação das forças produtivas, de modo que tal forma seja particularmente adequada à tarefa de desenvolvê-las. Em nossa época, ademais,

[...] as relações de produção capitalistas tendem a introduzir uma degeneração qualitativa das forças produtivas, à medida que os problemas que afetam indivíduos e sociedade são escamoteados mediante formas sempre renovadas de consumo que requerem novas forças produtivas cada vez mais alienadas do que se poderia considerar como necessidades "legítimas" (Singer, 1981, p. 26).

Por conseguinte, a tarefa não consistiria em conduzir as atuais forças produtivas ao seu desenvolvimento pleno, na expectativa de "um processo de tomada, pelos trabalhadores, de unidades de produção tecnicamente avançadas, que constituem o resultado do desenvolvimento capitalista e o ponto de partida do socialismo" (Germer, 2007, p. 64). Sendo o avanço das forças produtivas sempre historicamente determinado, isso significaria exacerbar o sentido dado a elas pelo capitalismo, em seus termos quantitativos e cumulativos, geradores de ciclos destrutivos sistêmicos, não de conjunturas revolucionárias. Alterar esse quadro demandaria instituir fins alternativos e racionalidades distintas, em termos qualitativos, seletivos e integradores, tendo em vista os riscos que comprometem a vida no futuro próximo e geram necessidades prementes, às quais a lógica de acumulação incessante não oferece respostas.

O desiderato do cooperativismo das classes trabalhadoras tem sido historicamente a criação de organizações ativas e sustentáveis, que brindem bem-estar e reduzam o seu grau de sujeição à economia capitalista. Em cenários futuros orientados à equidade e à democracia, em particular nos processos produtivos, às cooperativas de trabalhadores não faltam razões de se incorporarem e desempenharem papel relevante. Elas recuperam e revitalizam consignas seculares das lutas de resistência contra a exploração e a alienação, impostas principalmente por meio da autocracia patronal e gerencial. Igualmente, renovam as tentativas de materializar em níveis superiores valores como justiça, equidade e liberdade, fontes de grandes idealizações, em particular no ideário humanista e socialista. São impulsionadas por sua capacidade de responder a expectativas de direitos e dignidade, mas sua relevância em longo prazo dependerá de sua aptidão a propiciar uma vida melhor a amplos setores sociais e a sedimentar progressivas realizações sociais e econômicas.

Pode aplicar-se a elas um prognóstico similar àquele sobre as experiências de economia solidária: "Ainda que elas venham a desaparecer no futuro, constituem um tipo de movimento que deixará marcas, que ficará na história da classe trabalhadora, na memória não só dos seus atores, mas de toda a sociedade" (Leite, 2009, p. 39). Pouco será insistentemente reivindicável no plano dos arranjos institucionais, responsáveis pelo desenvolvimento regional, nacional e mundial, se não estiver realisticamente experimentado e incorporado no plano concreto das práticas de trabalho, de produção econômica e de participação cidadã. Enfrentar duríssimas contingências não é um demérito dos trabalhadores cooperados. Sua virtude consiste em não se resignar à imobilidade enquanto não se tenha enfraquecido e vencido a ordem mundial vigente, sobretudo porque, como adverte Gorender (1999), estão superados os tempos dos determinismos e das reiterações teleológicas.

\section{Notas}

1 O Mapeamento equivale tecnicamente a um levantamento amplo de informações, não a um censo ou a uma pesquisa amostral. Ainda assim, como agrega 
informações sobre empreendimentos localizados em 2.274 municípios, nas 27 Unidades Federativas, pode ser considerado representativo da economia solidária no Brasil.

2 O paradigma refere-se a princípios basilares, que têm orientado e animado o movimento cooperativista desde os Pioneiros de Rochdale (1844) e sua posterior adoção pela Aliança Cooperativa Internacional (1895), que os reafirmou e atualizou recentemente, por ocasião do seu centenário (Namorado, 1995).

3 A multiplicação de cooperativas solidárias é compreensível também de um ponto de vista pragmático. Embora exista um hiato flagrante entre o estatuto cooperativo instituído pela Lei 5.764/71 e as aspirações da economia solidária, o direito econômico brasileiro não oferece alternativas adequadas à legalização de empresas formadas a partir da associação de pessoas, delas querendo participar em igualdade de condiçōes e de poder decisório, sem fins precipuamente lucrativos. Empresas recuperadas, iniciativas de crédito solidário e empreendimentos de produção ou prestação de serviços via de regra apenas podem estabelecer-se mediante sua formalização como cooperativas.

4 A visível expansão das cooperativas agropecuárias, nas décadas de 1970 e 1980, em áreas onde era marcante a presença da pequena e da média propriedade familiar, decorreu da ação direta dos governos e da sua vinculação a um só organismo federal, o Ministério da Agricultura, o que oportunizou uma política de desenvolvimento mais uniforme para esse tipo de cooperativa, em detrimento dos demais.

5 Recorde-se ademais que a legislação nacional, incluindo as formas de organização e representação das cooperativas, foi estabelecida à época do regime militar e carece de legitimidade democrática para atrair novos setores, salvo por razóes pragmáticas e geralmente alheias aos princípios do cooperativismo.

6 O que não quer dizer que as cooperativas em questão passem a ser, elas próprias, indutoras da flexibilização do trabalho, uma questão geralmente mal compreendida. Para o trabalhador, o problema não é tanto a variabilidade da sua taxa de ocupação, pois, embora intensificada no cenário mais recente da economia, ela é característica de inúmeros setores, da produção familiar agrícola a todos aqueles onde predomina o trabalho autônomo, o pequeno comércio e as práticas de subcontratação. O problema principal é a instabilidade do vínculo de trabalho, quesito em que os empreendimentos representam um elemento progressivo, ao estabeleceram um ponto de referência ou de fixação do trabalhador, diante do qual ele não está imobilizado em um papel passivo, como ocorre no vínculo assalariado.

7 Ao fazer tais comparaçōes, é preciso manter o senso de realidade e verificar o que os trabalhadores ganham ou perdem nos empreendimentos solidários em relação às demais alternativas concretamente ao seu dispor, o que via de regra exclui, nos dias de hoje, serem assalariados de empresas sólidas e modernas, com vínculo empregatício regular e os respectivos direitos sociais garantidos.

8 A recomendação, redigida em 1866, foi adotada como resolução pelo I Congresso da Associação Internacional dos Trabalhadores, realizada naquele ano em Genebra. Apenas a partir de 1889, durante a Segunda Internacional, o movimento operário viria a cindir gradualmente o seu braço cooperativo de sua frente sindical e partidária, sobretudo em prol dessa última. Isto não ocorreu já no pós-1848 e tampouco engendrou uma clivagem definitiva, graças à qual as cooperativas teriam deixado de ser um "obstáculo ao avanço da luta pelo socialismo, uma vez que desviavam os esforços dos trabalhadores da esfera significativa da luta pelo poder do Estado" (Germer, 2007, p. 57). Essa versão, ainda corrente no debate marxista, apenas reflete uma das posições políticas da época, a mesma que, sob o comando intelectual de Lênin, conduziria à Revolução de 1917 e à conclusão fantasiosa de que esse trunfo deu início à realização prática do socialismo moderno, instaurando o poder do proletariado e garantindo a realização das aspirações históricas da classe operária.

9 Com exceção das cooperativas resultantes da tomada e recuperação de empresas capitalistas pelos trabalhadores e das cooperativas de produção agrícola criadas pelo Movimento dos Trabalhadores Rurais Sem Terra, ambas dotadas de princípios comuns e de organizaçôes representativas.

10 A criação de falsas cooperativas, classificadas normalmente como "de trabalho", inflacionou grandemente as cifras do setor cooperativo e provocou inúmeras críticas, alimentando também a descrença quanto à cooperativa em si. As estatísticas não permitem distinguir as cooperativas autênticas das falsas, missão que tem recaído sobre os órgãos fiscalizadores (não sem gerar contestações quanto ao seu excessivo rigor) e aos estudos sobre o cooperativismo de trabalho (Lima, 2002, 2004, 2006; Piccinini, 2004; Druck e Franco, 2007).

11 Por ser de resposta múltipla, a questão gerou números e percentuais sobrepostos.

12 Um histórico recente dessas pesquisas encontra-se em 
Gaiger e Corrêa (2010). A questão de fundo por certo não é original nos estudos sobre a cooperação produtiva (cf. Défourny, 1988). Na América Latina, os créditos por sua elaboração teórico-conceptual inicial devem ser atribuídos especialmente a Luis Razeto (cf. Guerra, 2002).

13 Esse último trabalho é de interesse particular, por ser um estudo comparado de 35 empresas entregues aos trabalhadores pelo governo de Salvador Allende. Cotejando seus dados com vasta literatura sobre o tema, conclui que há uma relação nitidamente positiva entre participação e produtividade, com destaque à maior eficácia das novas formas de controle social, exercidas pelos trabalhadores, e aos efeitos das retribuiçōes e estímulos coletivos sobre a inovação gerencial e produtiva (pp. 163-234). Além disso, constata a influência do contexto nacional da época, dado o projeto socialista da Unidade Popular e as políticas setoriais condizentes com essa orientação. Enquanto perdurou uma conjuntura política e econômica globalmente favorável no país, as empresas de trabalhadores evidenciaram com maior nitidez o seu potencial econômico e social.

14 Os EES pontuam em cada coeficiente à medida que apresentam propriedades, registradas pelo formulário de coleta do Mapeamento, vinculadas a um conjunto de Indicadores, condizentes com cada Dimensão e Vetor do modelo analítico. Detalhes técnicos do método de análise podem ser consultados em Gaiger (2007b).

15 A melhor remuneração média dos sócios nas cooperativas de trabalho observa-se nas faixas de 1 a 2 salários-mínimos $(25,7 \%$, contra $7,5 \%$ do total de empreendimentos) e de 2 a 5 salários-mínimos (15,6\% contra $3,2 \%)$. Em contrapartida, os benefícios sociais, que as cooperativas deveriam oferecer por meio de medidas alternativas ao garantido pelo vínculo empregatício convencional, são uma de suas sérias debilidades, embora as cooperativas de trabalho apresentem índices relativamente melhores.

16 O tema foi desenvolvido extensivamente em trabalho anterior (Gaiger, 2007c). Sobre o conceito de modo de produção, ver Giannotti (1976) e Gorender (1978).

\section{BIBLIOGRAFIA}

ANJOS, Eliene dos. (2009), "As singularidades das cooperativas autênticas". Trabalho apresentado no XIV Congresso Brasileiro de Sociologia, Rio de Janeiro.
CHANIAL, Philippe \& LAVILLE, Jean-Louis. (2009), "Associativismo", in A. Cattani et al. (orgs.), Dicionário internacional da outra economia, Coimbra, Almedina, pp. 21-25.

CULTI, Maria. (2008), "O cooperativismo popular no Brasil: importância e representatividade”. Disponível em <http://www.ecosol.com. br/publicacoes $>$, acessado em maio de 2008.

DEFOURNY, Jacques. (1988), “Coopératives de production et entreprises autogérées: une synthèse du débat sur les effets économiques de la participation". Mondes en Développement, XVI (61): 139-53.

DRUCK, Graça \& FRANCO, Tânia. (2007), $A$ perda da razão social do trabalho: terceirização $e$ precarização. São Paulo, Boitempo.

EDELWEIN, Karen. (2011), Economia solidária: a produção dos sujeitos (des)necessários. Jundiaí, SP, Paco Editorial.

ESPINOZA, Juan \& ZIMBALIST, Andrew. (1984), Democracia económica: la participación de los trabajadores en la industria chilena, 19701973. Cidade do México, Fondo de Cultura Económica.

ESTRIN, Saul; JONES, Derek \& SVEJNAR, Jan. (1987), "The Productivity Effects of Worker Participation: Producer Cooperatives in Western Economies". Journal of Comparative Economics, 11: 40-61.

FAIRBAIRN, Brett. (2004), "La provincia cooperativa de Canadá: individualismo y mutualismo en una sociedad de colonos, 1905-2005". Cayapa, 4 (8): 70-101.

FRANÇA FILHO, Genauto et al. (orgs.). (2006), Ação pública e economia solidária: uma perspectiva internacional. Porto Alegre, Editora da UFRGS.

GAIGER, Luiz (org.). (1996), Formas de resistência e de combate à pobreza. São Leopoldo, Unisinos.

(2001), "Virtudes do trabalho nos empreendimentos econômicos solidários". Revista Latinoamericana de Estudios del Trabajo, VII (13): 191-211.

. (ORG.). (2004), Sentidos e experiências da economia solidária no Brasil. Porto Alegre, editora da UFRGS. 
(2006), "A racionalidade dos formatos produtivos autogestionários". Sociedade e Estado, 21 (2): 513-544.

. (2007A), "Nouvelles formes de production non capitalistes au Brésil”. Revue Tiers Monde, 190: 309-324.

. (2007B), "A outra racionalidade da economia solidária: Conclusões do primeiro Mapeamento Nacional no Brasil". Revista Critica de Ciências Sociais, 79: 57-77.

(2007C), "La economía solidaria y el capitalismo en la perspectiva de las transiciones históricas", in J. Coraggio (org.), La economía social desde la periferia; contribuciones latinoamericanas, Buenos Aires, Altamira, pp. 79-109.

(2011), "Relações entre equidade e viabilidade nos empreendimentos solidários". Revista Lua Nova, 83: 79-109.

GAIGER, Luiz \& ASSEBURG, Benno. (2007), "A economia solidária diante das desigualdades". Dados Revista de Ciências Sociais, 50 (3): 499-533.

GAIGER, Luiz \& CORREAA, Andressa. (2010), “A história e os sentidos do empreendedorismo solidário”. Otra Economía, 7 (2): 153-176.

GAIGER, Luiz \& LAVILLE, Jean-Louis. (2009), "Economia solidária", in A. Cattani et al. (orgs.), Dicionário internacional da outra economia, Coimbra, Almedina, pp. 162-168.

GERMER, Claus. (2007), "A 'economia solidária': uma crítica marxista”. Estudos de Direito Cooperativo e Cidadania, 1: 51-73.

GIANNOTTI, José (1976), "Notas sobre a categoria "modo de produção" para uso e abuso dos sociólogos”. Estudos Cebrap, 17: 161-168.

GODELIER, Maurice. (1981), "D’un mode de production à l'autre: théorie de la transition". Recherches Sociologiques, Louvain-la Neuve, 12 (2): 161-193.

GORENDER, Jacob. (1978), O escravismo colonial. 2 ed. São Paulo, Ática (col. Ensaios, 29).

(1999), Marxismo sem utopia. São Paulo, Ática.

GUERRA, Pablo. (2002), Socioeconomia de la solidaridad. Montevidéu, Nordan - Comunidad.

HESPANHA, Pedro. (2010), "Microempreendedorismo popular e economia solidária: o sen- tido de uma mudança”. Otra Economía, 7 (2): 111-130.

HOLZMANN, Lorena. (2012), "Empreendimentos solidários e agentes externos: Autonomia ou tutela?", in I. Georges e M. Leite (orgs.), Novas configuraçoes do trabalho e economia solidária. São Paulo, Annablume, pp. 269-286.

LEITE, Márcia. (2009), "A economia solidária e o trabalho associativo: teorias e realidades". Revista Brasileira de Ciências Sociais, 24 (69): 31-51.

LIMA, Jacob. (2002), As artimanhas da flexibilização: o trabalho terceirizado em cooperativas de produção. São Paulo, Terceira Margem.

(2004), "O trabalho autogestionário em cooperativas de produção: o paradigma revisitado". Revista Brasileira de Ciências Sociais, 29 (56): 45-62.

(2006), "Cooperativas falsas ou coopergatos", in A. D. Cattani e L. Holzmann (orgs.), Dicionário de trabalho e tecnologia, Porto Alegre, Editora da UFRGS, pp. 71-77.

(2008), "Reestruturação industrial, desemprego e autogestão: as cooperativas do Vale dos Sinos". Sociologias, 10 (19): 212-249. (2009), "Cooperativas de trabalho", in A. Cattani et al. (orgs.), Dicionário internacional da outra economia, Coimbra, Almedina, pp. 91-95.

MARX, Karl. ([1866] 1982), Instruções para os delegados do conselho geral provisório: as diferentes questôes. Lisboa/Moscou, Editorial "Avante!"/ Edições Progresso. Disponível em <http:// www.marxists.org/portugues/marx/1866/08/ instrucoes.htm>.

NAMORADO, Rui. (1995), Os princípios cooperativos. Coimbra, Fora do Texto.

(2007), "Cooperativismo: história e horizontes”. Estudos de Direito Cooperativo e Cidadania, 1: 9-35.

NUNES, Christiane. (2001), "Cooperativas, uma possível transformação identitária para os trabalhadores do setor informal". Sociedade e Estado, 16 (1/2): 134-158.

PICCININI, Valmíria. (2004), "Cooperativas de trabalho de Porto Alegre e flexibilização do trabalho. Sociologias, VI (12): 68-104. 
PINTO, João. (2006), Economia solidária: de volta à arte da associação. Porto Alegre, Editora da UFRGS.

PONTES, Daniele. (2007), "Configuraçôes contemporâneas do cooperativismo brasileiro". Estudos de Direito Cooperativo e Cidadania, 1: 89-112.

SANTOS, Aline. (2008), "O processo de trabalho capitalista e a dinâmica das fábricas recuperadas". Economia Solidária e Ação Cooperativa, 2 (2): 77-89. (2010), O movimento da economia solidária no Brasil e os dilemas da organização popular. Tese de Doutorado, Rio de Janeiro, Programa de Pós-Graduação em Serviço Social da UERJ.

SCHNEIDER, José \& LAUSCHNER, Roque. (1979), "Evolução e situação atual do cooperativismo brasileiro". O Cooperativismo no Brasil: Enfoques, análises e contribuição. Rio Grande do Sul, Friedrich Neumann/Associação de Orientação às Cooperativas, pp. 1-58.

SINGER, Paul. (1981), O que é socialismo, hoje. Petrópolis, Vozes. (2002), "A recente ressurreição da economia solidária no Brasil", in B. S. Santos, Produzir para viver: os caminhos da produção não capitalista, Rio de Janeiro, Civilização Brasileira, pp. 81-130.

VERONESE, Marília. (2008), Psicologia social e economia solidária. São Paulo, Ideias \& Letras. 


\section{A ECONOMIA SOLIDÁRIA E A REVITALIZAÇÃO DO PARADIGMA COOPERATIVO}

\section{Luiz Inácio Gaiger}

Palavras-chave: Autogestão; Cooperativismo; Movimento operário; Solidariedade; Trabalho.

A economia solidária compreende um amplo conjunto de experiências que revigoram as tradiçóes associativas dos trabalhadores, graças à sua ênfase na autogestão, à sua abordagem crítica da ordem capitalista e à impulsão que propiciam a novos atores sociais, do plano local ao global. Nesse contexto, novas cooperativas de produção e de prestação de serviços, cuja racionalidade integra quesitos de solidarismo e de empreendedorismo, têm desenvolvido igualmente as dimensões sociais e políticas da empresa econômica, em favor dos trabalhadores, de sorte que o campo heterogêneo e controverso do cooperativismo sofre questionamentos e processos de renovação. Justifica-se com isso a retomada de questôes referentes ao sentido histórico das práticas e da identidade cooperativa. $\mathrm{O}$ artigo desenvolve esses temas em perspectiva histórica, a partir de revisão bibliográfica e de diversas pesquisas empíricas, com destaque aos dados do primeiro Mapeamento Nacional da Economia Solidária no Brasil.

\section{SOLIDARY ECONOMY AND THE REVITALIZATION OF THE COOPERATIVE PARADIGM}

\author{
Luiz Inácio Gaiger
}

Keywords: Self-management; Cooperative system; Solidarity; Labor movement; Work.

Solidary economy encompasses a range of experiences that invigorate the workers' associative traditions due to its emphasis on self-management, its critical approach to the capitalist order and the impulsion it propitiates to new social actors, both at the local and the global level. In this context, new cooperatives of production and services, whose rationality involves aspects of solidarity and entrepreneurship, have been developing the social as well the political dimensions of the economic enterprise in favor of the workers. Therefore, the heterogeneous and controversial field of the cooperative system is undergoing processes of questioning and renovation. This article develops these themes on a historical perspective, based on bibliographical revision and empirical research, highlighting especially data provided by the first National Mapping of Solidary Economy.

\section{L'ÉCONOMIE SOLIDAIRE ET LA REVITALISATION DU PARADIGME COOPÉRATIF}

\section{Luiz Inácio Gaiger}

Mots-clés: Autogestion; Coopérativisme; Mouvement ouvrier; Solidarité; Travail.

L'économie solidaire inclut un large éventail d'expériences qui revigorent les traditions associatives des travailleurs grâce à son accent sur l'autogestion, à son approche critique de l'ordre capitaliste et à l'impulsion qu'elle apporte aux nouveaux acteurs sociaux, du niveau local au global. Dans ce contexte, de nouvelles coopératives de production et de services, dont la rationalité engage aussi bien l'esprit d'entreprise que celui de la solidarité, ont également développé les dimensions sociales et politiques de l'action économique en faveur des travailleurs, de sorte que le domaine de la coopération, hétérogène et controversé, en subit des questionnements et des processus de renouvellement. Cela justifie la reprise des questions relatives au sens historique des pratiques et de l'identité coopérative. L'article reprend ce sujet selon une perspective historique et à partir d'une révision de la littérature et des différentes études empiriques, en particulier par rapport aux données du premier Recensement National de l'Économie Solidaire au Brésil. 